REVISTA ALAMEDAS Vol. 4, n. 2, 2016 e-ISSN 1981-025

\title{
RAZÕES HISTÓRICO-SOCIAIS PARA TUTELA JURÍDICA DO TRABALHO PRODUTIVO FEMININO E OS INSTRUMENTOS NORMATIVOS/PROTETIVOS BRASILEIROS

\author{
Cyrce Aryadne Souza ${ }^{1}$
}

Resumo: Apesar da conquista de diversos direitos pelas mulheres ao longo dos últimos anos, elas continuam sofrendo preconceitos e preterição no mercado de trabalho. O Direito do Trabalho, por meio das lutas e reivindicações do movimento feminista e sindical, apresenta disposições normativas direcionadas para a consolidação de uma tutela jurídica da trabalhadora, a fim de promover a entrada feminina no mercado de trabalho, seja coibindo atitudes discriminatórias, seja através das ações de ações afirmativas. Nessa perspectiva, demonstra-se a relevância da presente pesquisa, a qual tem por objeto analisar a evolução normativa dos direitos femininos, em especial àqueles referentes ao Direito do Trabalho. Para tanto, primeiro se aborda as raízes históricosociais do preconceito enfrentado pelas mulheres no campo laboral. Posteriormente, são mencionadas as Convenções da Organização Internacional do Trabalho (OIT) que dispõem sobre o trabalho feminino. Na parte final serão analisadas as principais evoluções normativas acerca da tutela jurídica das mulheres no Brasil. Para o desenvolvimento da presente pesquisa desenvolveuse estudo teórico acerca da temática proposta, através da revisão bibliográfica de diversos autores que abordaram assuntos relativos ao tema escolhido.

Palavras-chave: Discriminação; Mulheres; Tutela.

Abstract: Despite the achievement of many rights by women over the past few years, they continue to suffer prejudice and breach in the labor market. The Labour Law, through the struggles and demands of the feminist and trade union movement, has regulatory provisions directed to the consolidation of a legal protection of working to promote women's entry into the labor market, is curbing discriminatory attitudes, either through actions of affirmative action. From this perspective, it demonstrates the relevance of this research, which has the purpose to analyze the normative evolution of women's rights, especially those relating to labor law. To do so, it first addresses the historical and social roots of prejudice faced by women in the labor field. Subsequently, they are mentioned Conventions of the International Labour Organization (ILO) that have on female labor. In the final part will be considered the main regulatory developments on the legal protection of women in Brazil. For the development of this research was developed theoretical study on the theme proposed by literature review of several authors who discussed issues related to the chosen topic.

Key-words: Discrimination; Women; Protection.

\section{Introdução}

Inegável os avanços e as vitórias normativas alcançadas pelas mulheres nos últimos anos, em especial na seara laboral. Entretanto, apesar da conquista de diversos direitos, as mulheres continuam sofrendo preconceitos e preterição no mercado de trabalho. Além das empresas que

1 Mestre em Sociedade, Cultura e Fronteiras pela Universidade Estadual do Oeste do Paraná UNIOESTE/ Foz do Iguaçu. Contato: cdireito2008@gmail.com 
REVISTA ALAMEDAS Vol. 4, n. 2, 2016 e-ISSN 1981-025

optam por não as contratar, por entenderem que o custo de manter uma empregada mulher é mais alto, há ainda a diferença salarial a que são submetidas.

A inserção e crescimento de mulheres no mercado de trabalho podem ser confirmadas pelos dados oficiais. De acordo com a Relação Anual de Informações Sociais (RAIS) referente ao ano de 2013, divulgado pelo Ministério do Trabalho e Emprego, as mulheres já são maioria nos empregos que exigem formação técnica, representando 55\% desse segmento (MTE, 2014).

Estudo do IBGE de 2009 (IBGE, 2014), indica que a renda média do homem brasileiro é maior. De acordo com a pesquisa um homem ganha em média $\mathrm{R} \$ 1.522,00$ (mil quinhentos e vinte e dois reais) por mês, enquanto uma mulher recebe $R \$ 1.123,00$ (mil cento e vinte e três reais).

Se comparadas as áreas de atuação, os salários também são menores. Pessoas na faixa dos 25 anos ou mais, atuando nos ramos de Ciências Sociais, negócios e Direito, ganham em média $\mathrm{R} \$ 4.650,90$ (quatro mil seiscentos e cinquenta reais) se forem homens e $\mathrm{R} \$ 3.081,40$ (três mil e oitenta e um reais e quarenta centavos) se forem mulheres. Já no setor de engenharia, produção e construção, os homens recebem em média $\mathrm{R} \$ 5.985,60$ (cinco mil novecentos e oitenta e cinco reais e sessenta centavos) e as mulheres $\mathrm{R} \$ 3.976,10$ (três mil novecentos e setenta e seis reais e dez centavos) (IBGE, 2014).

Em contrapartida as mulheres apresentam maior formação educacional, o que demonstra que, apesar dos avanços, a mulher ainda enfrenta uma sociedade marcada pelo machismo no mundo do trabalho, por meio de práticas de discriminação direta e indireta seja no acesso ao emprego, na progressão de suas carreiras, nos salários e na própria decisão patronal sobre a manutenção do vínculo empregatício (IBGE, 2014).

O Direito do Trabalho, historicamente, por meio das lutas e reivindicações do movimento feminista e sindical, apresenta disposições normativas direcionadas para a consolidação de uma tutela jurídica da trabalhadora, a fim de promover a entrada feminina no mercado de trabalho, seja coibindo atitudes discriminatórias, seja através das ações de ações afirmativas.

Dessa forma, o presente artigo analisará a evolução da tutela jurídica protetiva do trabalho feminino, abordando as principais evoluções e modificações, bem como debatendo as razões histórico sociais do preconceito e discriminação ainda enfrentado pelas mulheres no mercado de trabalho. 
REVISTA ALAMEDAS Vol. 4, n. 2, 2016 e-ISSN 1981-025

\section{Razões histórico-sociais do preconceito enfrentado pela mulher no mercado de trabalho e diplomas protetivos da oit e do Brasil}

$\mathrm{O}$ debate de gênero vem ganhando amplitude no espaço jurídico. Como exemplo tem-se a Lei $\mathrm{n}^{\circ}$. 11.340/2006 que usa a palavra gênero para definir uma categoria, não se limitando a diferenciação biológica do sexo. Até então o termo era utilizado principalmente pela Antropologia e a Sociologia e essa utilização traz um novo panorama para a o Direito.

Essa questão emergencial surge de uma dívida historicamente contraída. Inegável as barreiras e o incômodo preconceito de gênero presente ainda nos dias de hoje com relação à mulher. Como exemplo, tem-se a discriminação direta e indireta testemunhada até hoje no ambiente de trabalho. Nessa perspectiva persiste a necessidade da tutela jurídica do trabalho da mulher.

A história da mulher é a história do homem, construída e redigida por eles e não por elas (DUBY; PERROT, 1995, p. 07). O reflexo desta construção se encontra presente nos variados âmbitos sociais e de sociabilização, resultando em um árduo processo de desconstrução destas marcas históricas no que diz respeito às "funções sociais" do homem e de sua produção. Não é por acaso que mulheres vêm reivindicando direitos, justamente porque esses lhes foram historicamente negados pela sociedade (DUBY; PERROT, 1995, p. 07).

Os motivos pelos quais as mulheres foram privadas de tais direitos fundamentam-se na estrutura de uma sociedade patriarcal (SCHOLZ, 1996, p. 30), em que a invisibilidade da mulher em detrimento da superioridade do homem esteve presente na constituição e reprodução dos espaços.

A sociedade patriarcal ocidental atual se estruturou na divisão antagônica do espaço e do trabalho, sendo da mulher o espaço doméstico e o trabalho reprodutivo e do homem o espaço público e o trabalho produtivo. Sendo assim, pode-se afirmar que na construção histórico-social de nossa sociedade a rua pertenceu ao homem, enquanto a casa destinou-se a mulher (SCHOLZ, 1996, p. 30).

Entretanto, a divisão social pautada pelo gênero destes espaços não definiu a autoridade de comando e a autonomia sobre eles, tendo em vista que a casa ficou sobre a responsabilidade da mulher, porém a ela não cabia à tomada de decisões, mas sim a organização e manutenção 
REVISTA ALAMEDAS Vol. 4, n. 2, 2016 e-ISSN 1981-025

desta. Ou seja, destinava-se a mulher o trabalho doméstico e destinava-se ao homem o trabalho produtivo, ambos sob o comando das estruturas patriarcais (LOP, 2009, p. 240).

Amauri Mascaro Nascimento (2011, p. 909), destaca algumas iniciativas de tutela jurídica do trabalho produtivo feminino no contexto da Revolução Industrial, visto que pelo menor custo financeiro, o trabalho da mulher era preferível ao do homem e essa realidade levou à criação do que pode ser considerada uma das primeiras medidas jurídicas que protegeram o trabalho feminino. Segundo o autor, no ano de 1942 ficou proibido na Inglaterra o trabalho feminino em espaços subterrâneos. Nesse mesmo período França e Alemanha também deram espaço a algumas normas de proteção ao trabalho da mulher.

O conceito de divisão sexual do trabalho (HIRATA; KERGOÀT, 2007, p. 596), é entendido como a divisão do trabalho social resultado das relações de divisão entre os sexos, que é construída historicamente e socialmente. Nesse sentido, o homem torna-se prioritário na esfera produtiva e as mulheres na esfera reprodutiva. Cabendo aos homens a apropriação das funções prioritárias, pertencendo a aqueles os espaços de excelência em um determinado contexto social produtivo.

Esse conceito torna-se assim uma importante ferramenta de análise da priorização e hierarquização das atividades laborais, evidenciando as desigualdades estruturais que criam um sistema de gênero e destacando o uso de uma ideologia naturalista como base (HIRATA; KERGOÀT, 2007, p. 599).

Helena Sumiko Hirata e Danièle Kergoat (2007, p. 595-609), questionam a segmentação do mercado de trabalho no que diz respeito aos processos de profissionalização, ocupações e suas destinações segundo o sexo a qual pertenciam, evidenciando as construções históricas e culturais presente nesses processos.

Os estudos do processo de inserção da mulher no mercado de trabalho, marcado por continuidades e descontinuidades (ARAÚJO, 2008, p. 88), deram destaque às diferenças e desigualdades presentes nas condições de trabalho entre trabalhadores e trabalhadoras em distintos locais de trabalho.

Os estudos sobre o sindicalismo e as diferenças produzidas nos ambientes sindicais também demonstraram as assimetrias de poder que excluíam as mulheres e tornavam invisibilizadas suas lutas e resistências (CAPPELLIN, 1994, p. 271-290). A partir de então, os discursos feministas começaram a ganhar forças nas discussões de gênero dentro dos sindicatos, 
havendo um crescimento na participação das mulheres, que atribuíam ao controle e poder masculino a divisão sexual das atividades laborais.

As mudanças socioeconômicas e políticas dos anos 90, marcado pelas diversas transformações e novas formas de manejo de produção e de trabalho, impulsionadas pela reestruturação de sistemas mundiais, deram um novo enfoque para as relações de gênero e trabalho. Ou seja, as mulheres passaram a ocupar mais postos de trabalho, porém submetidas a um salário inferior e outras condições precarizantes, tais como subcontratações e contratos por tempo determinado (MONTAGNER, 2004, p. 72).

Segundo Hirata e Kergoàt (2007, p. 602-603), há dois pontos fortes na discussão de uma nova modalidade da divisão do trabalho, sendo "(i) a reorganização do trabalho nos espaços, como a externalização do trabalho doméstico e (ii) uma nova divisão dessa modalidade de trabalho, também pelo aumento de número de mulheres em profissão de nível superior acompanhado do crescente número de mulheres em situações precárias".

Os estudos das recentes mudanças nos ambientes de trabalho sob uma perspectiva de gênero dão destaque à crescente entrada das mulheres no trabalho extra doméstico (ARAÚJO, 2008, p. 94). Também são investigadas as consequências desse movimento, tais como: a) o aumento na ocupação de postos ditos masculinos pelas mulheres, que antes eram ocupados apenas por homens; b) as habilidades e competências associadas ao trabalho feminino flexível que tornaram preferencial a ocupação de mulheres em determinados cargos; c) a informalidade e precarização das condições de trabalho no que diz respeito às trabalhadoras.

A precarização e a segregação das trabalhadoras surgem como uma nova forma de desigualdade presente nas relações de trabalho, que não necessariamente apenas exclui, como nos antigos mecanismos, mas degrada e classificam, diversificando as formas de exclusão e segregação específicas de exploração das mulheres no mercado de trabalho (NEVES; PEDROSA, 2007, p. 30).

Assim, a conquista de participação ativa na sociedade (pela ocupação de cargos e tomada dos espaços produtivos) não exclui por si só a discriminação que as mulheres sofrem nos ambientes de trabalho como parte integrante do sistema da dominação masculina. Justamente por isso é que se faz necessário a promoção da igualdade através do Direito.

A dominação masculina se faz presente no campo simbólico, onde essa dominação faria parte de uma violência simbólica. Pierre Bourdieu (1999, p. 160), chama atenção a essas formas 
de manutenção de um poder que se encontra travestido nas relações, que subjetiviza o pensamento e a concepção de mundo. Segundo o mesmo autor as relações de poder estão presentes na própria concepção de masculino e feminino, que são baseadas em um modo de pensar dicotômico e de oposição. As concepções subjetivas, dominadas pela separação e segregação dualista e hierárquica, formam esquemas de pensamento, que acreditam serem livres, porém esses pensamentos "livres" estão marcados por interesses e preconceitos e também pela violência simbólica (BORDIEU, 1999, p. 160).

Desta forma, nas relações desiguais de poder existiria certa aceitação inconsciente dos grupos dominados, uma subordinação que antecederia a reflexão. Essas subordinações inconscientes estariam marcadas pela socialização dos corpos, na naturalização destes, baseado em uma visão androcêntrica (BORDIEU, 1999, p. 160).

$\mathrm{Ou}$ seja, a dominação masculina ocorre principalmente no campo simbólico, pela naturalização dos corpos, pela separação dicotômica da sociedade e pela separação de suas atividades e ramos, que acaba por segregar, não necessariamente de forma consciente, os grupos dominados.

Após a entrada da mulher no mercado de trabalho, é notória a segregação do trabalho feminino, pois apesar do aumento da influência feminina nos espaços de trabalho, esses espaços continuam separados. Conforme Lais Abramo (2008, p. 78), há delimitações da mulher a determinados tipos de atividades, justamente pela construção e dominação masculina do espaço do trabalho e de suas relações, onde as justificativas giram em torno da naturalização dos corpos. Essas segregações e limitações impedem o direito a igualdade real de oportunidades e de tratamento.

A igualdade de gênero busca, portanto, o acesso a direitos iguais, a oportunidades e ao mesmo tratamento para homens e mulheres, defendendo os direitos das pessoas e o acesso aos recursos independentemente do seu sexo. Entretanto, não quer dizer que homens e mulheres sejam iguais, e nem que devem se tornar, mas sim pressupõe que homens e mulheres são livres para desenvolver suas capacidades e ter o direito de decisão sobre elas, sem limitações construídas e reafirmadas pelo imaginário coletivo, se guiando por estereótipos e preconceitos sobre a divisão dos "papéis" que cabem a estes.

A tutela jurídica do trabalho produtivo feminino, nessa perspectiva, justifica-se e destinase à "pacificação" do conflito social existente nas relações de gênero, que se estendem às relações 
REVISTA ALAMEDAS Vol. 4, n. 2, 2016 e-ISSN 1981-025

de trabalho, tanto no que diz respeito à exclusão de mulheres no mercado de trabalho, quanto na posição de subalternidade e precariedade do trabalho feminino.

O Direito deve acompanhar o movimento dinâmico da sociedade, caso contrário deixa de ser uma ferramenta contra a diferença, e se transforma em poder conservador (LOPES, 2006, p. 408). As mulheres reivindicam um papel transformador pelo Direito, de forma a proporcionar mecanismos de combate a sua histórica de exclusão e inferioridade.

Com a Constituição Federal de 1988 exigiu-se a adaptação das regras jurídicas, pelos princípios de proibição de discriminação em relação a sexo e a abolição da "chefia" da sociedade conjugal. Com isso, no âmbito civil, promulgou-se um novo Código Civil, no ano de 2002, e no âmbito trabalhista ocorreram várias alterações legislativas, assegurando o combate à discriminação e promoção da igualdade.

A promoção das normas para a igualdade de gênero também é uma das responsabilidades centrais da Organização Internacional do Trabalho (OIT). A atuação da instituição ao longo dos anos demonstra a centralidade dessa temática (OIT, 2013).

A primeira intervenção da OIT foi através de Convenção $\mathrm{n}^{\circ}$. 03, de 1919, que tratava sobre o emprego da mulher antes e após o nascimento do filho. Após essa primeira tratativa, é possível observar a intensa luta do órgão na promoção da igualdade de gênero.

Na década de 1950 as ações da OIT se voltavam à promoção da igualdade de condições de emprego e de remuneração (OIT, 2013). Nessa época se estabelece o princípio da não discriminação com base em vários fundamentos, incluindo o sexo, no que concerne ao acesso à formação profissional, ao acesso ao emprego, e aos termos e condições de emprego.

A partir da década de 1960 (OIT, 2013), as normas de promoção da igualdade basearamse cada vez mais no reconhecimento de que a igualdade de gênero implica partilha das responsabilidades familiares entre homens e mulheres. À medida que as mulheres ocupavam um lugar crescente no mercado do trabalho - embora nem sempre em empregos a tempo integral - a figura masculina como responsável pelo sustento familiar, representava cada vez menos o modelo do trabalhador "típico".

No início da década de 1980 (OIT, 2013), o foco da análise sobre a igualdade em geral foi reorientado das mulheres para o relacionamento entre mulheres e homens. Nessa perspectiva, ganhou terreno a convicção de que qualquer mudança no papel das mulheres deveria ser 
REVISTA ALAMEDAS Vol. 4, n. 2, 2016 e-ISSN 1981-025

acompanhada de uma alteração no papel dos homens e deveria refletir-se na maior participação daqueles na família e nas tarefas domésticas. Os instrumentos aplicam-se tanto aos homens como as mulheres, com responsabilidades em relação a crianças dependentes ou outros membros da sua família próxima e tem como objetivo facilitar o emprego feminino sem discriminação com base nessas responsabilidades.

A OIT continuou atuando na busca de igualdade de gênero na década de 1990, e a Declaração sobre os Princípios e Direitos Fundamentais no Trabalho e seu Acompanhamento, de 1998, define as áreas dos direitos e os princípios fundamentais que devem ser promovidos e realizados e inclui expressamente como quarto direito fundamental a eliminação da discriminação relativamente ao emprego e a profissão, aspecto esse em que se insere a igualdade entre mulheres e homens do mundo do trabalho (OIT, 2013).

Essa Declaração também afirma expressamente que os Membros da OIT têm a obrigação de respeitar, promover e realizar os princípios relativos a estes direitos fundamentais independentemente da ratificação das Convenções e Recomendações pertinentes a essas matérias (OIT, 2013).

A OIT (2013), indica algumas diretrizes para a igualdade entre mulheres e homens no trabalho, dentre elas: a promoção da igualdade de gênero através das normas internacionais do trabalho; a defesa de progressos mensuráveis para atingir a igualdade de gênero com os seus constituintes (governos e organizações de empregadores e trabalhadores) e nas suas próprias estruturas e processos; a promoção da igualdade de gênero através da cooperação técnica em todo o mundo; a promoção da igualdade de gênero através da gestão, disseminação e partilha de informação pertinente.

Dentro da política histórica de busca, pela OIT, da igualdade de gênero, seu Conselho de Administração, em 2005, tornou obrigatória a integração da perspectiva de gênero em todas as atividades de cooperação técnica da Instituição (OIT, 2013).

Um conceito chave na atuação da OIT sobre essa temática é o planejamento de gênero. Este pode ser definido, segundo a OIT, como o planejamento que integra a igualdade entre homens e mulheres e considerações sobre o empoderamento das mulheres - ferramentas para a integração da perspectiva de gênero (OIT, 2013).

A análise de gênero possibilita uma ferramenta para o diagnóstico das diferenças entre mulheres e homens relativamente às suas atividades, condições, necessidades, acesso e controle 
REVISTA ALAMEDAS Vol. 4, n. 2, 2016 e-ISSN 1981-025

de recursos específicos, bem como no seu acesso aos benefícios do desenvolvimento e à tomada de decisão (FOLLADOR, 2009, p. 14). Essa análise estuda as ligações entre estes e outros fatores num contexto social, econômico, político e ambiental abrangente.

A perspectiva de proposta de empoderamento das mulheres, seja no mercado de trabalho ou mesmo no ambiente doméstico constitui o primeiro passo para o planejamento estratégico e para o desenvolvimento sensível à dimensão do gênero. Abrange a coleta de dados desagregados por sexo e a informação sensível à dimensão de gênero sobre a população a ser tratada, a identificação da divisão sexual do trabalho e do acesso e controle dos recursos e benefícios respectivamente por homens e mulheres, a compreensão das necessidades e oportunidades das meninas, rapazes, mulheres e homens, a identificação dos obstáculos em um contexto mais abrangente e a reavaliação das capacidades das organizações relevantes na promoção igualdade de gênero (OIT, 2013).

Nesse sentido, tem-se o atual estudo apresentado pela OIT (2015), que apresentou que as mulheres ainda estão longe do empoderamento. $\mathrm{O}$ estudo demonstra que as mulheres hoje são donas ou gerenciam mais de $30 \%$ de todas as empresas, mas tendem a se concentrar em micro e pequenas empresas, sendo que apenas 5\% dos CEOs das maiores empresas do mundo são mulheres. O estudo apresenta outros dados impactantes, os quais merecem atenção e estudos específicos.

Se a situação global quanto a igualdade de gênero é preocupante, tal realidade também se observa no Brasil, que possui mecanismos que visam coibir a discriminação e promover a real igualdade de gêneros.

A Constituição Federal proclamada em 1988 traz um novo paradigma para a posição feminina na sociedade brasileira. $\mathrm{O}$ texto constitucional vigente garantiu à mulher a equidade expressa de direitos em relação aos homens, coibindo a discriminação por gênero e trazendo mecanismos efetivos de concretização do mandamento constitucional.

O princípio da igualdade faz jus ao destaque por ser um instituto de extrema importância que, na Constituição Federal, foi assentado como um dos direitos invioláveis, ao lado da vida e da liberdade. Entretanto a igualdade a que se refere à Constituição Federal não é a ausência absoluta da diferença. O que se deseja é a consideração da diferença, devendo algumas serem minimizadas enquanto outras, maximizadas. Ainda que a abertura do princípio da isonomia também estivesse 
presente em outros diplomas legais anteriores ao texto constitucional vigente, era precário para coibir a discriminação à mulher.

Dessa forma, era forçoso estabelecer o princípio da equidade paralelamente às medidas afirmativas, já que as diferenças entendidas como excludentes - a necessidade de auxílio maternidade, o direito a amamentação, dentre outras - são exteriores as vontades da trabalhadora, visto que não se escolhe ser mulher. Portanto o sexo não pode ser um fardo que impede o acesso ou permanência no trabalho. É nesse sentido que as normas protetivas do trabalho feminino se alocam.

Historicamente, a mulher encontrava-se, na sociedade brasileira, em uma circunstância de inferioridade em relação ao homem, condição decorrente de questões econômicas, culturais e sociais. Destaca-se que almejar que apenas a fórmula da lei seja suficiente para superar esse cenário de limitação e equiparar homens e mulheres seria um engano. A história social brasileira caracteriza-se pelo patriarcalismo ocidental, herdado dos portugueses, e o Direito reproduzia essa realidade por meio de normas jurídicas que legitimavam a ideia de superioridade masculina ou, pelo menos, de hipossuficiência das mulheres (FOLLADOR, 2009, p. 08).

A ação das mulheres pela igualdade se deu em toda América Latina, repercutindo em suas legislações internas. Não se aspirava a masculinização da mulher, mas sim o respeito à dignidade da pessoa humana, anterior a sua condição de mulher (ABRAMO, 2008, p. 79). No campo das relações trabalhistas, para além da previsão constitucional da igualdade entre os gêneros e proibição de discriminação, a Consolidação das Leis de Trabalho (CLT) também se tornou um importante diploma legal de proteção.

Importante observar que a CLT é de 1943, ou seja, muito anterior à própria Constituição Federal, razão pela qual diversas alterações e emendas foram necessárias, a fim de adequar tal diploma aos valores expressos no texto constitucional. Diferentemente do ocorrido com relação ao Direito Civil, em que foi instituído novo Código posterior à Constituição Federal vigente, o Direito do Trabalho permanece tendo como texto central a CLT. Diante desse fato, diversas Ações Direta de Inconstitucionalidade foram propostas para determinar a recepção e a extensão da interpretação de dispositivos celetistas.

Assim, antes da Constituição de 1988, numa intencionalidade de proteger a mulher, várias atividades foram proibidas legalmente a estas, o que reforçava o viés discriminatório. Nesse sentido, foi definida constitucionalmente em 1934 a proibição do trabalho no período noturno à 
REVISTA ALAMEDAS Vol. 4, n. 2, 2016 e-ISSN 1981-025

mulher. Na promulgação da Constitucional de 1988, não havia mais essa distinção entre os sexos e a Lei $n^{\circ} .7 .855$ de 24 de outubro de 1989 revogou os artigos da CLT que proibiam o trabalho noturno às mulheres.

Existia a necessidade de garantir, com medidas de proteção e ação especial, a mulher no período de gravidez, de parto, de amamentação e impossibilidade para levantamento de excesso de peso. A primeira ação legal efetivada com relação a maternidade foi a Lei $\mathrm{n}^{\circ} .6 .136$, de 7 de novembro de 1974 a qual criou o salário-maternidade previdenciário (ANSILIERO, 2007). Contemporaneamente, o salário-maternidade é regulado pela Lei $n^{\circ}$. 10.710/2003. Conforme esta lei, a empresa deve pagar o salário devido à empregada, possibilitando a compensação com outras contribuições previdenciárias devidas pela empresa.

O período de licença maternidade era de 84 dias e foi aumentado pela Constituição Federal de 1988 para 120 dias de afastamento. A Lei 11.770, de 09 de setembro de 2009, prevê o Programa Empresa Cidadã, que prorroga a licença-maternidade das gestantes que trabalharem nas empresas participantes do programa para um período de 180 dias. Para tanto, as mulheres interessadas deverão solicitar a ampliação da licença até o primeiro mês após o parto, ficando impedidas de exercer qualquer atividade remunerada ou manter a criança em instituições escolares ou creches. A empresa deverá pagar os salários integrais às empregadas, podendo descontar integralmente o valor nas parcelas do Imposto de Renda.

Quanto à capacidade para fins trabalhistas, tanto o homem como a mulher adquire plenamente aos 18 anos, revogando os dispositivos contrários existentes na CLT de 1943. A emenda Constitucional n ${ }^{\circ}$ 20, de 1998, dispõe, ressalvada a condição de aprendiz a partir dos 14 anos, como idade mínima de 16 anos para empregar-se em atividade não nociva ao desenvolvimento, sendo necessária a autorização dos pais ou responsável, até atingir sua plena capacidade.

O tema proteção a mulher no mercado de trabalho, não foi tratado nas Constituições anteriores, trata-se, portanto, de inovação da Constituição de 1988. As vitórias das mulheres no mercado de trabalho não vieram de graça. Intensas discussões e pressão popular foram necessárias para que cada direito fosse conquistado. É importante ressaltar que é na área laboral que se concentram grande parte dos avanços do Estado Democrático de Direito, que podem ser visualizados na busca por isonomia e melhores condições de trabalho. Inegável a centralidade 
que o trabalho representa na vida social. Dessa forma, os avanços no campo do Direito do Trabalho devem refletir as buscas populares.

Isso porque o Direito do Trabalho é entendido como ramo do Direito Social que estimula “[...] o desenvolvimento de práticas emancipatórias a partir de um equacionamento crítico da realidade, pondo em questão a relação do homem com o trabalho no contexto da sociedade capitalista" (MAIOR, 2011, p. 621). Sendo o trabalho central para a sociedade, a exclusão ou a colocação de obstáculos para o acesso da mulher pode ser extremamente nocivo, pois representaria uma negação a um direito fundamental de participação e inclusão social.

Tem-se que ao trabalho é atribuído valor social máximo, pois está disposto como fundamento da República junto à livre iniciativa e ao princípio da dignidade da pessoa humana. Essa tríade normativa poderá ser vista novamente no artigo 170 da Constituição Federal, que ao descrever os princípios da ordem econômica dispõe que "a ordem econômica, fundada na valorização do trabalho humano e na livre iniciativa, tem por fim assegurar a todos existência digna, conforme os ditames da justiça social [...]" (BRASIL, 1988). Encontra-se, também, no artigo 193 do mesmo diploma legal que "a ordem social tem como base o primado do trabalho, e como objetivo o bem-estar e a justiça sociais" (BRASIL, 1988).

Esse antagonismo de interesses presentes na Constituição Federal - valor social do trabalho e da livre iniciativa - representa a construção histórica dos direitos sociais, e por consequência do próprio Direito do Trabalho, que apesar de ainda ser visto por muitos como um direito corporativista, de classe, ou melhor, como direito dos trabalhadores frente aos capitalistas, não há mais espaço, socialmente, para um direito que não leve em conta a pluralidade de interesses em jogo, tal como demonstra Aldacy Rachid Coutinho (2010, p. 164):

Ora, o direito do trabalho não é o direito dos "trabalhadores", mas a regulamentação de uma relação de emprego, o direito do capitalismo, estatuindo regras também em favor do capital, o que por si só afasta o "mito do bom direito". Aliás, se a proteção também não fosse um mito, o fim da relação de emprego não seria expresso juridicamente na forma de um direito potestativo do empregador, que esconde práticas discriminatórias, mas agasalharia a teoria da pressuposição ou da causalidade.

É a partir dessa reflexão que se conclui que o trabalho é o "centro convergente dos direitos sociais" (SALGADO apud DELGADO, 2008, p. 55). Dessa forma, o trabalho não se 
REVISTA ALAMEDAS Vol. 4, n. 2, 2016 e-ISSN 1981-025

presta apenas para a produção, uma vez que é por meio do trabalho que as pessoas sustentam a si e a sua família, assim sendo, as formas de trabalho predatórias devem ser abolidas, pois desarmonizam o indivíduo e a própria sociedade, desestabilizando os núcleos familiares (ARAÚJO, 2008, p. 74).

Assim, o Direito do Trabalho limita a exploração do trabalhador e garante meios de luta e reconhecimento de direitos a eles, sendo resultado tanto da ação destes e de suas organizações em face da ordem capitalista (direito conquistado), como também produto do embate político dos empresários contra a ação desses mesmos trabalhadores (direito concedido) (LOPEZ apud SANTOS , 2010, p. 168).

A breve análise histórico-jurídica demonstra quanto em menos de cem anos foi alterado o regime jurídico da mulher, especialmente nas relações de trabalho. As transformações foram expressivas, conquanto ainda aquém do ideal, tanto para os direitos dos trabalhadores quanto para o debate de gênero. Mesmo demonstrando interesse sobre a proteção da dignidade e condições de trabalho existem ainda problemas tão antigos como a discriminação direta ou indireta ao trabalho produtivo feminino, a mão de obra escrava infantil e adulta, que assombram o mundo do trabalho.

\section{Considerações Finais}

O tema abordado é relevante, tanto do ponto de vista histórico-social, como do ponto de vista jurídico, trata-se de objeto de estudo que conduz o olhar do pesquisador para o debate sobre a conceituação e concretização do princípio da igualdade e sobre a hermenêutica dos direitos fundamentais e, especificamente no campo juslaboral, sobre o regime jurídico do trabalho produtivo feminino.

Além disso, o tema envolve a relação isonômica entre homens e mulheres e a vedação ao tratamento discriminatório, passando pela análise da discriminação negativa e positiva, bem como as ações afirmativas referentes às mulheres.

Ficou demonstrado que a sociedade brasileira ainda possui traços patriarcais, os quais acabam explicando alguns dispositivos legais ainda existentes no ordenamento jurídico.

Também ficou demonstrado os avanços sociais e legais no reconhecimento dos direitos das mulheres, em especial na atuação da Organização Internacional do Trabalho (OIT). 
REVISTA ALAMEDAS Vol. 4, n. 2, 2016 e-ISSN 1981-025

\section{REFERÊNCIAS}

ABRAMO, Lais. A Situação da Mulher LatinoAmericana - O Mercado de Trabalho no Contexto da Reestruturação. In: DELGADO, Dídice, CAPELLIN, Paola \& SOARES, Vera (Orgs.). Mulher e Trabalho: experiências de ação afirmativa. São Paulo: ELAS/Boitempo Editorial, 2000.

ARAÚJO, Eduardo Marques Vieira. Movimentos sociais e a verdadeira valorização do trabalho sob a perspectiva constitucional. In: HENRIQUE, Carlos Augusto Junqueira et al. Trabalho e movimentos sociais. Belo Horizonte: Del Rey: 2008. p. 69-92.

ANSILIERO, Graziela. Histórico e Evolução Recente da Concessão de Salários-Maternidade no Brasil. Informe de Previdência Social, v. 19, n. 2, fev/2007, p. 1-20, p. 02. Disponível em: Disponível em: 〈http://www.mpas.gov.br/arquivos/office/3_090213-144507-483.pdf〉. Acesso em 22 de ago. 2016.

BRASIL. Constituição da República Federativa do Brasil de 1988. Diário Oficial da República Federativa do Brasil, DF, 5 out. 1988. Disponível em: <http://www.planalto.gov.br/ccivil_03/Constituicao/Constituiçao.htm〉. Acesso em 22 de ago. 2016.

BRASILPOST. ONU estima em 81 anos o prazo para se atingir a equidade de gênero. Disponível em: <http://www.brasilpost.com.br/2015/03/07/tempo-equidadegeneros_n_6823612.html>. Acesso em 22 de ago. 2016.

BOURDIEU, Pierre. A Dominação masculina. 2 ed. Rio de Janeiro: Bertrand, 1999.

CAPPELLIN, Paola. Viver o sindicalismo no feminino. Estudos Feministas, n. especial, Rio de Janeiro CIEC/ECO/UFRJ, 1994, p. 271-290. Disponível em <https://periodicos.ufsc.br/index.php/ref/article/viewFile/16110/14824>. Acesso em 22 de ago. 2016.

COUTINHO, Aldacy Rachid et al. A autonomia privada: em busca da defesa dos direitos fundamentais dos trabalhadores. In: SARLET, Ingo Wolfgang (Org.). Constituição, direitos fundamentais e direito privado. 3. ed. Porto Alegre: Livraria do Advogado, 2010. p. 159-173.

DUBY, Georges e PERROT, Michelle. Escrever a História das Mulheres. In: THÉBAUD, Françoise. História das Mulheres no Ocidente: o século XX. Porto, Edições Afrontamento, 1995.

FOLLADOR, Kellen Jacobsen. A mulher na visão do patriarcado brasileiro: uma herança ocidental. Revista fato\&versões, v.1, n.2, p. 3-16, 2009. Disponível em: <http://revista.catolicaonline.com.br:81/revistadigital/index.php/fatoeversoes/article/viewFile/3/1 02>. Acesso em 22 de ago. 2016. 
REVISTA ALAMEDAS Vol. 4, n. 2, 2016 e-ISSN 1981-025

HIRATA, Helena Sumiko; KERGOAT, Danièle. Novas configurações da divisão sexual do trabalho. Cadernos de Pesquisa, v. 37, n. 132, p. 595-609, set./dez. 2007, p. 596. Disponível em: 〈http://www.scielo.br/pdf/cp/v37n132/a0537132.pdf>. Acesso em 22 de ago. 2016.

IBGE. O trabalho da mulher principal responsável no domicílio. Disponível em: <http://www.ibge.gov.br/home/estatistica/indicadores/trabalhoerendimento/pme_nova/trabalho_ mulher_responsavel.pdf >. Acesso em 22 de ago. 2016.

- Pesquisa Mensal de Emprego - PME. Disponível em: <http://www.ibge.gov.br/home/estatistica/indicadores/trabalhoerendimento/pme_nova/Mulher_M ercado_Trabalho_Perg_Resp.pdf $>$. Acesso em 22 de ago. 2016.

LOP, Elizandra. Condição da mulher como propriedade em sociedades patriarcais. Visão Global, Joaçaba, v. 12, n. 2, p. 231-250, jul./dez. 2009, p. 240. Disponível em: <http://editora.unoesc.edu.br/index.php/visaoglobal/article/view/623>. Acesso em 22 de ago. 2016.

MAIOR, Jorge Souto. Curso de direito do trabalho: teoria geral do direito do trabalho. São Paulo: LTr, 2011. v. I. pt. I.

MONTAGNER, Paula. A Reestruturação Produtiva e o Desemprego da Mulher. In: COSTA, Ana Alice, et al. (Org). Reconfiguração das relações de gênero no trabalho. São Paulo: CUT, 2004, p. 71-81, p. 72.

NASCIMENTO, Amauri Mascaro. Curso de direito do trabalho. 20. ed. rev. atual. São Paulo: Saraiva, 2011.

NEVES, Magda de Almeida; PEDROSA, Célia Maria. Gênero, flexibilidade e precarização: o trabalho a domicílio na indústria de confecções. Sociedade e Estado, Brasília, v. 22, n. 1, p. 1134, jan./abr 2007. Disponível em: 〈http://www.scielo.br/pdf/se/v22n1/v22n1a02.pdf>. Acesso em 22 de ago. 2016.

NOGUEIRA, Vera Maria Ribeiro. Direitos Humanos - a antinomia igualdade X equidade. Anais do XVIII Seminário Latinoamericano de Escuelas de Trabajo Social - La custión social y la formación profesional em Trabajo Social em el contexto delas nuevas relaciones de poder y la diversidad latinoamericana; San José - Costa Rica, de 12 a 14 de julho de 2004. Disponível em <http://www.ts.ucr.ac.cr/binarios/congresos/reg/slets/slets-017-038.pdf〉. Acesso em: 22 out. 2014.

OIT. A importância da igualdade de gênero no mundo do trabalho. Disponível em: $<$ http://www.oitbrasil.org.br/content/importancia-da-igualdade-de-genero-no-mundo-dotrabalho>. Acesso em 22 de ago. 2016.

. ABC dos direitos das mulheres trabalhadoras e igualdade de gênero. Disponível em: $<\mathrm{http} / /$ www.oitbrasil.org.br/content/importancia-da-igualdade-de-genero-no-mundo-dotrabalho>. Acesso em 22 de ago. 2016. 
ONU. Igualdade de gênero no trabalho continua insuficiente, diz OIT. Disponível em: <http://nacoesunidas.org/igualdade-de-genero-no-trabalho-continua-insuficiente-diz-oit/>. Acesso em 22 de ago. 2016.

PORTAL MTE. Características do Emprego Formal - RAIS 2013 - Principais Resultados. Disponível em: <http://www.ibge.gov.br/home/estatistica/indicadores/trabalhoerendimento/pme_nova/Mulher_M ercado_Trabalho_Perg_Resp.pdf $>$. Acesso em 22 de ago. 2016.

SANTOS, Ronaldo Lima. Fraudes nas relações de trabalho: morfologia e transcendência. Revista do Tribunal Regional do Trabalho da $15^{\text {a }}$ Região, Campinas, n. 36, p. 165-189, 2010. Disponível em: <http://bdjur.stj.jus.br/xmlui/bitstream/handle/2011/41908/fraudes_nas_relacoes_santos.pdf?sequ ence $=1>$. Acesso em 22 de ago. 2016.

SCHOLZ, Roswitha. O valor é o homem. Teses sobre a socialização pelo valor e a relação entre os sexos. Novos Estudos - CEBRAP, São Paulo, n. 45, p. 15-36, jul/1996, p.30. Disponível em: <http://obeco.planetaclix.pt/rst1.htm>. Acesso em 22 de ago. 2016. 